Int. J. Electrochem. Sci., 14 (2019) $7594-7607$

International Journal of

ELECTROCHEMICAL

SCIENCE

www.electrochemsci.org

\title{
Effect of Tensile Deformation on Microstructure and Pitting Resistance of BFS600 Austenitic High-strength Stainless Steel
}

\author{
Yawen Cheng, Yuanyuan Liu*, Guangming Liu, Jiaming Wang, Shengsheng Qian, Jin Li, \\ Yiming Jiang*
}

Department of Materials Science, Fudan University, Shanghai 200433, People's Republic of China *E-mail: liuyy@fudan.edu.cn; ymjiang@fudan.edu.cn.

doi: $10.20964 / 2019.08 .37$

Received: 16 March 2019 / Accepted: 20 May 2019 / Published: 30 June 2019

\begin{abstract}
BFS600 austenitic stainless steel is a newly developed Cr-Mn-Ni-N high-strength stainless steel that aims to be used in the automotive industries. The effects of tensile deformation on the microstructure evolution and pitting behaviors of the BFS600 stainless steels were investigated in this paper. The microstructure and magnetic properties of the tensile-deformed BFS600 stainless steels were evaluated using optical microscopy, x-ray diffraction, scanning electron microscopy, electron backscatter diffraction, the measurement of saturation magnetization and the ferrite meter. It was revealed that the $\alpha^{\prime}$-martensite phase had appeared in the steel after the tensile deformation. No $\varepsilon$-martensite phase was identified in this work. The amount of the $\alpha^{\prime}$-martensite phase increased as the tensile strain increased. Tensile deformation also resulted in the increase of dislocation density and grain refinement of the BFS600 stainless steel. For the deformed BFS600 austenitic stainless steels, the pitting resistance in $\mathrm{NaCl}$ solution decreased first and then increased as the tensile strain increased from 0 to $50 \%$. The worst pitting resistance was present for the sample with a tensile strain of $30 \%$. The dependence of pitting resistance on the tensile strain can be attributed to the combination effects of the increased dislocation density, the transformation of $\gamma$ phase to $\alpha^{\prime}$-martensite phase, and the grain refinement after the tensile deformation.
\end{abstract}

Keywords: High strength stainless steel, Strain induced martensite, Microstructure characterization, Tensile deformation, Pitting resistance

\section{$\underline{\text { FULL TEXT }}$}

(C) 2019 The Authors. Published by ESG (www.electrochemsci.org). This article is an open access article distributed under the terms and conditions of the Creative Commons Attribution license (http://creativecommons.org/licenses/by/4.0/). 